\title{
Thrombocytopenia in pregnant women with Plasmodium falciparum malaria in an area of unstable malaria transmission in eastern Sudan
}

\author{
Mayyada B Adam', Gamal K Adam², Duria A Rayis ${ }^{1}$, Mustafa I Elbashir ${ }^{1}$ and Ishag Adam ${ }^{1 *}$
}

\begin{abstract}
Background: Blood platelet levels are being evaluated as predictive and prognostic indicators of the severity of malaria infections in humans. However, there are few studies on platelets and Plasmodium falciparum malaria during pregnancy.

Methods: A case-control study was conducted at Gadarif Hospital in Eastern Sudan, an area characterized by unstable malaria transmission. The aim of the study was to investigate thrombocytopenia in pregnant women with P. falciparum malaria (cases) and healthy pregnant women (controls).

Results: The median (interquartile) platelet counts were significantly lower in patients with malaria $(\mathrm{N}=60)$ than in the controls $(N=60), 61,000(43,000-85,000)$ vs. 249,000 $(204,000-300,000) / \mu \mathrm{L}$, respectively, $p<0.001$. However, there was no significant difference in the platelet counts in patients with severe $P$. falciparum malaria $(N=12)$ compared with those patients with uncomplicated P. falciparum malaria $(N=48), 68,000(33,000-88,000) / \mu \mathrm{L}$ vs. 61 , $000(45,000-85,000) / \mu \mathrm{L}$, respectively, $p=0.8$. While none of the control group had thrombocytopenia (platelet count $<75,000 / \mu \mathrm{L})$, it was found that $6 / 12(50 \%)$ and $27 / 48(56.2 \%)(p<0.001)$ of the patients with severe malaria and uncomplicated malaria had thrombocytopenia, respectively. Pregnant women with $P$. falciparum malaria, compared with the pregnant healthy control group, were at higher risk $(\mathrm{OR}=10.1,95 \% \mathrm{Cl}=4.1-25.18 ; p<0.001)$ of thrombocytopenia. Two patients experienced bleeding, and there was one maternal death due to cerebral malaria where the patient's platelet count was only $28,000 / \mu \mathrm{L}$.
\end{abstract}

Conclusion: P. falciparum malaria is associated with thrombocytopenia in pregnant women in this setting. More research is needed.

\section{Background}

It has been estimated that, each year, 30.3 million African women become pregnant in malaria endemic areas [1]. Pregnant women are more susceptible to malaria infections than their non-pregnant counterparts [2]. Malaria during pregnancy is associated with poor maternal and fetal outcomes [3]. In Sudan, pregnant women in the eastern and central regions are susceptible to malaria infection regardless of their age or parity $[4,5]$, and the disease is one of the leading causes of maternal and perinatal mortality [6-8].

Malaria, especially the severe Plasmodium falciparum form, can cause thrombocytopenia, where there is an

\footnotetext{
* Correspondence: ishagadam@hotmail.com

'Faculty of Medicine, University of Khartoum, P. O. Box 102, Khartoum, Sudan Full list of author information is available at the end of the article
}

abnormally low number of platelets, and activation of the coagulation cascade $[9,10]$. Hence, platelet count is being evaluated as a predictor and prognostic feature of malaria infection [11]. However, most research on thrombocytopenia and malaria is focused on nonpregnant populations including adults and children with symptomatic and asymptomatic $P$. falciparum infections [12-14]. There are few published data on platelets and $P$. falciparum infection during pregnancy [15]. The current study was conducted at Gadarif Hospital in Eastern Sudan to investigate thrombocytopenia in pregnant women infected with $P$. falciparum malaria parasites. The area is characterized by unstable malaria transmission; P. falciparum is the sole malaria species in the area [16], and the disease is a huge problem among pregnant women, regardless of their age or parity [17]. 


\section{Methods}

A case-control study was conducted at the antenatal clinic in Gadarif Maternity Hospital in Eastern Sudan during the rainy/post rainy season of June-November 2011. Cases were pregnant women with P. falciparum malaria confirmed by blood film examination. Controls were afebrile healthy pregnant women attending for routine antenatal care without any illness, history, or symptoms (headache, dizziness, joint pain, anorexia, nausea, spontaneous bleeding) suggestive of malaria. In addition, the controls had parasite negative blood films. After signing an informed consent form, the obstetrics history was taken from cases and controls using pre-test questionnaires. Pregnant women with a hypertensive disorder of pregnancy (blood pressure of $140 / 90 \mathrm{mmHg}$ or more, with or without proteinuria), or pregnant women using aspirin or heparin were not included in the case or control groups. The cases were examined thoroughly for signs of severe $P$. falciparum infection, and those with one or more criteria of severe malaria [18] were admitted to the hospital and managed accordingly, as we have recently described [19]. Women who had not fulfilled the criteria for severe infection were considered to have uncomplicated P. falciparum malaria and were treated with the first-line anti-malarial treatment (artesunatesulfadoxine-pyrimethamine) as out-patients according to the Sudanese National Malaria control policy [20].

Blood films were prepared and stained with Giemsa, and $100 \times$ oil immersion fields were examined. All the slides were double-checked blindly and only considered negative if no parasites were detected in 100 fields. Densities (parasite per $\mu \mathrm{L}$ of whole blood) were then calculated on the basis of the WBC count of the individual subjects. An average of 500 WBCs were counted for each subject before parasite densities were estimated. Thin blood films were used for parasite species identification.

Two $\mathrm{mL}$ of blood were collected from each woman in the case and control groups. The blood was collected into ethylenediaminetetraacetic acid anticoagulant through venipuncture and kept on a roller with constant mixing. The complete blood count was determined using a Sysmex automated hematology analyzer in the lab within one hour of collection. Sysmex accuracy was determined on a daily basis using manufacturerprovided samples with known cell counts.

\section{Statistics}

Data were entered in computer using SPSS (version 16.0 for Microsoft Windows) and double-checked before analysis. Continuous variables were checked for normality, and normally distributed data were described by the mean (standard deviation) and non-normally distributed data by the median (interquartile range). Categorical data were compared using a Chi-square test or a Fisher's exact test, as appropriate. Student's $t$-test and ANOVA were used to compare the means between two or three of the groups, respectively. Mann-Whitney and KruskalWallis $\mathrm{H}$ tests were used to analyze medians. A Pearson correlation test was performed between the platelets and parasite counts. Univariate and multivariate analyses were used, with thrombocytopenia (platelet count $<75,000 / \mu \mathrm{L})$ as the dependent variable, while age, parity, gestational age, and temperature were the independent factors. Odds ratios and 95\% confidence interval were calculated, and a $P$ value $<0.05$ was considered significant.

\section{Ethics}

The study received ethical clearance from the Research Board at the Faculty of Medicine, University of Khartoum, Sudan.

\section{Results}

Sixty pregnant women presented with $P$. falciparum malaria during the study period, and an equal number of healthy pregnant women were assigned to the control group. Out of the 60 P. falciparum-infected women, 12 were diagnosed as severe $P$. falciparum cases that exhibited various clinical manifestations, including, severe anemia (3), hypotension (9), jaundice (3), cerebral malaria (1), hyperparasitemia (5), bleeding (2) and more than one criteria (7).

While there were no significant differences in the mean values (SD) for the age, parity, gestational age, temperature, or the biochemical tests between the severe malaria, uncomplicated malaria and the control groups, the hemoglobin values were significantly lower in patients with severe malaria (Table 1). The parasite count ranged from 5400 to 148350 ring-form parasites/ $\mu \mathrm{L}$ with a geometric mean of 9225.7 rings $/ \mu \mathrm{L}$. None of

\section{Table 1 Comparing mean(SD) of the basic clinical data between the patients with $P$. falciparum malaria and} controls

\begin{tabular}{lcccc}
\hline Variables & $\begin{array}{l}\text { Patients } \\
\text { with severe } \\
\text { malaria } \\
(\boldsymbol{N}=\mathbf{1 2})\end{array}$ & $\begin{array}{l}\text { Patients with } \\
\text { uncomplicated } \\
\text { malaria } \\
(\boldsymbol{N}=\mathbf{4 8})\end{array}$ & $\begin{array}{c}\text { Controls } \\
(\boldsymbol{N}=\mathbf{6 0})\end{array}$ & $\boldsymbol{P}$ \\
\hline Age, years & $26.7(5.2)$ & $26.0(5.8)$ & $25.8(5.4)$ & 0.8 \\
\hline Parity & $3.0(1.6)$ & $3.2(2.6)$ & $2.4(2.0)$ & 0.1 \\
\hline Gestational age, weeks & $24.7(6.8)$ & $25(9.6)$ & $25.8(10.1)$ & 0.8 \\
\hline Temperature, $^{0} \mathrm{C}$ & $38.5(0.6)$ & $37.7(0.7)$ & $37.1(0.2)$ & 0.3 \\
\hline Haemoglobin, $\mathrm{g} / \mathrm{dl}$ & $9.1(2.2)$ & $10.2(1.6)$ & $11.3(1.3)$ & $<0.001$ \\
\hline Blood glucose, $\mathrm{mg} / \mathrm{dl}$ & $72.4(3.0)$ & $74.6(4.0)$ & - & 0.08 \\
\hline Serum bilirubin, $\mathrm{mg} / \mathrm{dl}$ & $2.0(0.7)$ & $1.8(0.6)$ & - & 0.3 \\
\hline Serum creatinine, $\mathrm{mg} / \mathrm{dl}$ & $1.0(0.2)$ & $1.0(0.3)$ & - & 0.9 \\
\hline
\end{tabular}


Table 2 Comparison of $\mathbf{n}(\%)$ of women with platelet concentration by categories $\times 1,000 / \mu \mathrm{L}$ between the cases and controls

\begin{tabular}{lllll}
\hline Platelets category & $\begin{array}{l}\text { Patients } \\
\text { with severe } \\
\text { malaria } \\
(\boldsymbol{N}=\mathbf{1 2})\end{array}$ & $\begin{array}{l}\text { Patients with } \\
\text { uncomplicated } \\
\text { malaria } \\
(\boldsymbol{N}=\mathbf{4 8})\end{array}$ & $\begin{array}{l}\text { Controls } \\
(\boldsymbol{N}=\mathbf{6 0 )}\end{array}$ & $\boldsymbol{P}$ \\
\hline$<50$ & $5(41.7)$ & $17(35.4)$ & $0(0.0)$ & $<0.001$ \\
\hline $50-74$ & $1(8.3)$ & $10(20.8)$ & $0(0.0)$ & 0.002 \\
\hline $75-99$ & $5(41.7)$ & $15(31.3)$ & $1(1.7)$ & $<0.001$ \\
\hline $100-149$ & $1(8.3)$ & $3(6.3)$ & $1(1.7)$ & 0.08 \\
\hline$\geq 150$ & $0(0.0)$ & $3(6.3)$ & $58(96.7)$ & $<0.001$ \\
\hline
\end{tabular}

these pregnant women had an enlarged spleen or liver. Two patients presented with nasal bleeding and bleeding of the gums.

While none of the controls had thrombocytopenia, it was found that 6/12 (50\%) and 27/48 (56.2\%), $p<0.001$, of the patients with severe $P$. falciparum malaria and uncomplicated $P$. falciparum malaria had thrombocytopenia, respectively (Table 2).

In patients with $P$. falciparum malaria, the platelet count ranged from 17,000 to $311,000 / \mu \mathrm{L}$. The median (interquartile range) of the platelets was significantly lower in patients with malaria (both severe and uncomplicated $P$. falciparum malaria) than in the controls, $61,000(43,000-85,000)$ vs. $249,000(204,000-300,000)$ (controls), $p<0.001$. However, there was no significant difference in the median (interquartile range) of the platelets in patients with severe malaria compared with those with uncomplicated $P$. falciparum malaria, 68,000 $(33,000-88,000)$ vs. $61,000(45,000-85,000)$, respectively, $p=0.8$, Figure 1 .
Table 3 Risk factors for thrombocytopenia using univariate and multivariate analyses

\begin{tabular}{llllllll}
\hline & \multicolumn{3}{l}{ Univariate analysis } & & \multicolumn{3}{c}{ Multivariate analysis } \\
\cline { 2 - 4 } The variable & OR & $\mathbf{9 5} \% \mathbf{C l}$ & $\boldsymbol{P}$ & & OR & $\mathbf{9 5} \% \mathbf{C l}$ & $\boldsymbol{P}$ \\
\hline Age & 0.9 & $0.9-1.0$ & 0.6 & & 1.0 & $0.9-1.1$ & 0.9 \\
\hline Primigravidae & 0.9 & $0.8-1.1$ & 0.6 & & 0.8 & $0.6-1.0$ & 0.3 \\
\hline Gestational age & 1.0 & $0.9-1.0$ & 0.9 & & 1.0 & $0.9-1.0$ & 0.6 \\
\hline Temperature & 0.9 & $0.8-1.0$ & 0.5 & 0.9 & $0.7-1.1$ & 0.4 \\
\hline Haemoglobin & 1.9 & $0.8-4.2$ & 0.1 & & 1.0 & $0.7-1.3$ & 0.8 \\
\hline Malaria & 8.5 & $3.6-20.8$ & $<0.001$ & 10.1 & $4.1-25.18$ & $<0.001$ \\
\hline
\end{tabular}

The univariate and multivariate analyses found that malaria was the only risk factor for thrombocytopenia (odds $\quad$ ratio $=10.1, \quad 95 \% \quad \mathrm{CI}=4.1-25.18 ; \quad p<0.001$ ) (Table 3). There was no significant correlation between the platelet levels and parasite counts $(r=0.124 ; \mathrm{P}=0.3)$. One patient died during resuscitation, after presenting with cerebral malaria and minor bleeding from the gums. This patient's hemoglobin and platelet counts were $5 \mathrm{~g} / \mathrm{dl}$ and 18,000 , respectively.

\section{Discussion}

To the best of our knowledge, this is the first published data on thrombocytopenia in pregnant women infected with $P$. falciparum malaria in Africa. The main findings of the current study were that the platelet counts in pregnant women with $P$. falciparum malaria were significantly lower than in the controls, and there was no difference in the platelet counts in women with severe $P$. falciparum malaria vs. in the women with uncomplicated malaria. One noteworthy finding was that pregnant women with malaria had a 10 times higher risk of

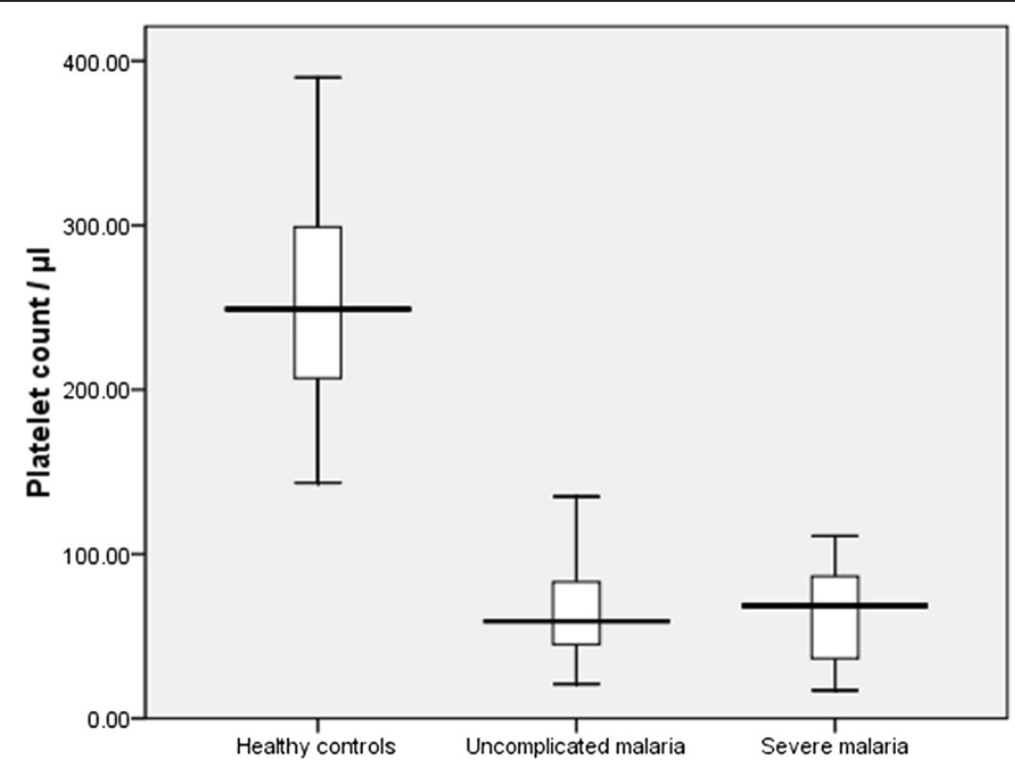

Figure 1 Comparing platelets count between the patients with $P$. falciparum malaria and controls. 
thrombocytopenia than did the controls. In women with $P$. falciparum malaria infections, there was no significant correlation between parasite and platelet counts. Recently, Tan et al. observed that pregnant women living at the Thai-Burmese border were more susceptible to thrombocytopenia (platelet counts $<150,000 / \mu \mathrm{L}$ ) than their non-pregnant counterparts; the median platelet counts $134,000(11,000-690,000)$ in this study were significantly lower in pregnant women with $P$. falciparum malaria and Plasmodium vivax malaria, with the first malaria episode increasing the risk of thrombocytopenia [15]. Interestingly, various definitions of platelet density (per $\mu \mathrm{L}$ ) have been used to define thrombocytopenia in pregnant women, i.e. $75,000 / \mu \mathrm{L}, 115,000 / \mu \mathrm{L}$ and $150,000 / \mu \mathrm{L}$, and of course, pregnancy itself can lead to thrombocytopenia [21-24]

In the current study, no correlation was found between the blood-stage parasite numbers and the platelet counts. This is in accordance with a previous observation, where it was shown that the pattern of thrombocytopenia and parasitemia did not have a linear relationship among malaria-infected Nigerian children [14]. However, among Papuan adults, platelet counts were negatively correlated with the level $P$. falciparum parasitemia [12]. Thrombocytopenia in malaria probably occurs through peripheral destruction, sequestration or excessive removal of the platelets by the spleen, as well as platelet consumption by the process of disseminated intravascular coagulation [25-28]. Platelets have been reported to enhance clumping of P. falciparum-infected erythrocytes, and this process might lead to pseudo thrombocytopenia [29]. In endemic areas, malaria patients have high levels of specific antibodies (IgG) which bind to platelet-bound malaria antigens [30].

In the current study, two patients presented with nasal bleeding and bleeding of the gums, and one of those who presented with cerebral malaria died. There were no episodes of bleeding or maternal death in our recent study on severe malaria among pregnant women in eastern Sudan [19]. Thrombocytopenia and spontaneous bleeding among pregnant women might cause life threatening antepartum or postpartum hemorrhages. Recent observations document that women with placental malaria are at higher risk of postpartum hemorrhage [31,32]. The question of malaria-associated hemorrhage in pregnancy might be addressed by longitudinal studies aimed at investigating the role played by platelets in peripheral and placental malaria.

In the current study, no significant difference was found in the platelet counts when patients with severe malaria were compared with those who had uncomplicated disease. This might be related to the small sample size in this study because only 12 patients presented with severe $P$. falciparum malaria. Nonetheless, Saravu et al. recently found that non-pregnant adult patients with severe $P$. falciparum malaria had a statistically significant lower platelet count than patients with uncomplicated malaria [33]. One of the limitations of the current study was the lack of the patients' outcomes in term of the treatment and the pregnancy outcomes.

\section{Conclusion}

P. falciparum malaria is associated with thrombocytopenia in pregnant women in eastern Sudan. More research is needed.

\section{Competing interests}

The authors declare that they have no competing interests.

\section{Authors' contributions}

MBA and IA carried out the study and participated in the statistical analysis. GKA and DAR participated in the clinical work and statistical analysis. MIE and DAR conducted the laboratory work. All the authors have read and approved the manuscript.

\section{Acknowledgments}

We are very grateful to the women who participated in this study and to all the staff at Gadarif hospital. This work was funded by the National Fund for Promotion of Medical Service, Khartoum, Sudan.

\section{Author details}

${ }^{1}$ Faculty of Medicine, University of Khartoum, P. O. Box 102, Khartoum, Sudan. 'Faculty of Medicine, Gadarif University, P. O. Box 63, Gadarif, Sudan.

Received: 26 March 2012 Accepted: 28 July 2012

Published: 6 August 2012

\section{References}

1. Dellicour S, Tatem AJ, Guerra CA, Snow RW, ter Kuile FO: Quantifying the number of pregnancies at risk of malaria in 2007: a demographic study. PLoS Med 2010, 7:e1000221.

2. Elghazali G, Adam I, Hamad A, El-Bashir Ml: Plasmodium falciparum infection during pregnancy in an unstable transmission area in eastern Sudan. East Mediterr Health J 2003, 9:570-580.

3. Brabin BJ: An analysis of malaria in pregnancy in Africa. Bull World Health Organ 1983, 61:1005-16.

4. Adam I, Babiker S, Mohmmed AA, Salih MM, Prins MH, Zaki ZM: ABO blood group system and placental malaria in an area of unstable malaria transmission in eastern Sudan. Malar J 2007, 6:110.

5. Adam I, Khamis AH, Elbashir MI: Prevalence and risk factors for Plasmodium falciparum malaria in pregnant women of eastern Sudan. Malar J 2005, 4:18.

6. Bader E, Alhaj AM, Hussan AA, Adam I: Malaria and stillbirth in Omdurman Maternity Hospital, Sudan. Int J Gynaecol Obstet 2010, 109:144-6.

7. Elhassan EM, Mirghani OA, Adam I: High maternal mortality and stillbirth in the Wad Medani Hospital, Central Sudan, 2003-2007. Trop Doct 2009, 39:238-9.

8. Haggaz AA, Radi EA, Adam I: High maternal mortality in Darfur, Sudan. Int J Gynaecol Obstet 2007, 98:252-3.

9. Erhart LM, Yingyuen K, Chuanak N, Buathong N, Laoboonchai A, Miller RS, Meshnick SR, Gasser RA Jr, Wongsrichanalai C: Hematologic and clinical indices of malaria in a semi-immune population of western Thailand. AmJTrop Med Hyg 2004, 70:8-14.

10. Abdalla S, Pasvol G: Platelets and blood coagulation in human malaria. In The Haemotology of Malaria. Edited by Newton PN, Essien E, White NJ. London: Imperial College Press; 2004:249-276.

11. Imbert P, Rogier C, Gerardin P: Letter to the editor. Am JTrop Med Hyg 2003, 68:380-381.

12. Taylor WR, Widjaja H, Basri H, Ohrt C, Taufik T, Tjitra E, Baso S, Fryauff D, Hoffman SL, Richie TL: Changes in the total leukocyte and platelet counts in Papuan and non Papuan adults from northeast Papua infected with 
acute Plasmodium vivax or uncomplicated Plasmodium falciparum malaria. Malar J 2008, 7:259.

13. Maina RN, Walsh D, Gaddy C, Hongo G, Waitumbi J, Otieno L, Jones D, Ogutu BR: Impact of Plasmodium falciparum infection on haematological parameters in children living in Western Kenya. Malar J 2010, 3(9):S4.

14. Jeremiah ZA, Uko EK: Depression of platelet counts in apparently healthy children with asymptomatic malaria infection in a Nigerian metropolitan city. Platelets 2007, 18:469-71.

15. Tan SO, McGready R, Zwang J, Pimanpanarak M, Sriprawat K, Thwai KL, Moo Y, Ashley EA, Edwards B, Singhasivanon P, White NJ, Nosten F: Thrombocytopaenia in pregnant women with malaria on the Thai-Burmese border. Malar J 2008, 7:209.

16. Malik EM, Atta HY, Weis M, Lang A, Puta C, Lettenmaier C: Sudan Roll Back Malaria Consultative Mission: Essential Actions to Support the Attainment of the Abuja Targets. Sudan RBM Country Consultative Mission Final Report. Geneva: Roll Back Malaria Partnership; 2004.

17. Adam I, Adamt GK, Mohmmed AA, Salih MM, Ibrahuim SA, Ryan CA: Placental malaria and lack of prenatal care in an area of unstable malaria transmission in eastern Sudan. J Parasitol 2009, 95:751-2.

18. World Health Organization: Division of control of tropical diseases: Severe falciparum malaria. Trans R Soc Trop Med Hyg 2000, 94:SI/1-SI/90.

19. Ali AA, Elhassan EM, Magzoub MM, Elbashir Ml, Adam I: Hypoglycaemia and severe Plasmodium falciparum malaria among pregnant Sudanese women in an area characterized by unstable malaria transmission. Parasit Vectors 2011, 23(4):88.

20. Adam I, Ali DM, Abdalla MA: Artesunate plus sulfadoxine-pyrimethamine in the treatment of uncomplicated Plasmodium falciparum malaria during pregnancy in eastern Sudan. Trans R Soc Trop Med Hyg 2006, 100:632-5.

21. Boehlen F: Thrombocytopenia during pregnancy. Importance, diagnosis and management. Hämostaseologie 2006, 26:72-74.

22. Matthews JH, Benjamin S, Gill DS, Smith NA: Pregnancy-associated thrombocytopenia: definition, incidence and natural history. Acta Haematol 1990, 84:24-29.

23. McCrae KR: Thrombocytopenia in pregnancy: differential diagnosis, pathogenesis, and management. Blood Rev 2003, 17:7-14.

24. Boehlen F, Hohlfeld P, Extermann P, Perneger TV, de Moerloose P: Platelet count at term pregnancy: a reappraisal of the threshold. Obstet Gynecol 2000, 95:29-33.

25. Beale PJ, Cormack JD, Oldrey TB: Thrombocytopenia in malaria with immunoglobulin (IgM) changes. BMJ 1972, 1(5796):345-349.

26. Ladhani S, Lowe B, Cole AO, Kowuondo K, Newton CR: Changes in white blood cells and platelets in children with falciparum malaria: relationship to disease outcome. Br J Haematol 2002, 119:839-847.

27. Skudowitz RB, Katz J, Lurie A, Levin J, Metz J: Mechanisms of thrombocytopenia in malignant tertian malaria. BMJ 1973, 2:515-518.

28. Essien EM: The circulating platelet in acute malaria infection. $\mathrm{Br} J$ Haematol 1989, 72:589-590.

29. Moulin F, Lesage F, Legros AH, Maroga C, Moussavou A, Guyon P, Marc E, Gendrel D: Thrombocytopenia and Plasmodium falciparum malaria in children with different exposures. Arch Dis Child 2003, 88:540-541.

30. Pain A, Ferguson DJ, Kai O, Urban BC, Lowe B, Marsh K, Roberts DJ: Plateletmediated clumping of Plasmodium falciparum-infected erythrocytes is a common adhesive phenotype and is associated with severe malaria. Proc Natl Acad Sci U S A 2001, 98:1805-1810.

31. Uddenfeldt Wort U, Hastings I, Bergstrom S, Massawe S, Lipingu C, Brabin BJ: Increased postpartum blood loss in pregnancies associated with placental malaria. Int J Gynaecol Obstet 2007, 96:171-175.

32. Piper C, Brabin BJ, Alpers MP: Higher risk of post-partum hemorrhage in malarious than in non-malarious areas of Papua New Guinea. Int J Gynaecol Obstet 2001, 72:77-78.

33. Saravu K, Docherla M, Vasudev A, Shastry BA: Thrombocytopenia in vivax and falciparum malaria: an observational study of 131 patients in Karnataka, India. Ann Trop Med Parasitol 2011, 105:593-598.

doi:10.1186/1472-6890-12-10

Cite this article as: Adam et al:: Thrombocytopenia in pregnant women with Plasmodium falciparum malaria in an area of unstable malaria transmission in eastern Sudan. BMC Clinical Pathology 2012 12:10.

\section{Submit your next manuscript to BioMed Central and take full advantage of:}

- Convenient online submission

- Thorough peer review

- No space constraints or color figure charges

- Immediate publication on acceptance

- Inclusion in PubMed, CAS, Scopus and Google Scholar

- Research which is freely available for redistribution 